\title{
Simultaneous conduction of two- and three-phase hollow-fiber-based liquid-phase microextraction for the determination of aromatic amines in environmental water samples
}

\author{
Yong Tao ${ }^{\mathrm{a}, \mathrm{b}}$, Jing-Fu Liu ${ }^{\mathrm{a}}$, Thanh Wang ${ }^{\mathrm{a}}$, Gui-Bin Jiang ${ }^{\mathrm{a}, \mathrm{b}, *}$ \\ a State Key Laboratory of Environmental Chemistry and Ecotoxicology, Research Center for Eco-Environmental Sciences, \\ Chinese Academy of Sciences, P.O. Box 2871, Beijing 100085, China \\ b School of Earth and Space Sciences, University of Science and Technology of China, Hefei 230026, China
}

\section{A R T I C L E I N F O}

\section{Article history:}

Received 26 July 2008

Received in revised form

14 November 2008

Accepted 17 November 2008

Available online 7 December 2008

\section{Keywords:}

Hollow-fiber-based liquid-phase

microextraction

Aromatic amines

High performance liquid chromatography

\begin{abstract}
A B S T R A C T
This paper describes a simultaneously performed two-/three-phase hollow-fiber-based liquid-phase microextraction (HF-LPME) method for the determination of aromatic amines with a wide range of $\mathrm{p} K_{\mathrm{a}}$ ( -4.25 to 4.6$)$ and $\log K_{\mathrm{ow}}(0.9-2.8)$ values in environmental water samples. Analytes including aniline, 4-nitroaniline, 2,4-dinitroaniline and dicloran were extracted from basic aqueous samples (donor phase, $\mathrm{DP}$ ) into the microliter volume of organic membrane phase impregnated into the pores of the polypropylene hollow fiber wall, then back extracted into the acidified aqueous solution (acceptor phase, AP) filling in the lumen of the hollow fiber. The mass transfer of the analytes from the donor phase through the organic membrane phase into acceptor phase was driven by both the counter-coupled transport of hydrogen ions and the $\mathrm{pH}$ gradient. Afterwards, the hollow fiber was eluted with $50 \mu \mathrm{L}$ methanol to capture the analytes from both the organic membrane and the acceptor phase. Factors relevant to the enrichment factors (EFs) were investigated. Under the optimized condition (DP: $100 \mathrm{~mL}$ of $0.1 \mathrm{M} \mathrm{NaOH}$ with $2 \mathrm{M} \mathrm{Na}_{2} \mathrm{SO}_{4}$; organic phase: di- $n$-hexyl with $8 \%$ trioctylphosphine oxide (TOPO); AP: $10 \mu \mathrm{L}$ of $8 \mathrm{M} \mathrm{HCl}$; extraction time of $80 \mathrm{~min}$ ), the obtained $\mathrm{EFs}$ were $405-2000$, dynamic linear ranges were $5-200 \mu \mathrm{g} / \mathrm{L}$ $(R>0.9976)$, and limits of detection were $0.5-1.5 \mu \mathrm{g} / \mathrm{L}$. The presence of humic acid $(0-25 \mathrm{mg} / \mathrm{L}$ dissolved organic carbon) had no significant effect on the extraction efficiency. The proposed procedure worked very well for real environmental water samples with microgram per liter level of analytes, and good spike recoveries (80-103\%) were obtained.
\end{abstract}

(c) 2008 Elsevier B.V. All rights reserved.

\section{Introduction}

Aromatic amines such as aniline and other substituted derivatives may be released from the manufacture of dyestuff, cosmetic and medicine, and as byproducts of energy technologies [1,2]. They can enter into the environment and experience complex environmental transformations at trace level. Generally, this class of compounds is considered hazardous to human health because they can be readily converted to carcinogenic $n$-nitroamines through reactions with nitrosylating agents in the environment $[3,4]$. Presently, these compounds have been listed in the priority pollutants by US Environmental Protection Agency (EPA) $[5,6]$. Thus, it is important to develop a rapid and sensitive analytical method to determine these compounds in environmental water.

\footnotetext{
* Corresponding author. Fax: +86 1062849179.

E-mail address: gbjiang@rcees.ac.cn (G.-B. Jiang).
}

Methods for preconcentration and detection of aromatic amines in environmental samples were mainly based on liquid-liquid extraction (LLE) [7], solid-phase extraction (SPE) [8] and liquid-liquid-liquid-phase microextraction (LLLME) [9] followed by high performance liquid chromatography (HPLC) with ultraviolet-visible or fluorescence detector, as well as solidphase microextraction (SPME) [10,1] and dispersive liquid-liquid microextraction (DLLME) with simultaneous derivatization followed by gas chromatography/mass spectrometry (GC-MS) [11].

To improve the stability and reliability of liquid-phase microextraction (LPME), Pedersen-Bjergaard and Rasmussen introduced hollow-fiber-based liquid-phase microextraction (HF-LPME) in 1999 [12]. In this microextraction technique, a water-immiscible organic solvent was immobilized in the pores of a porous hollow fiber by capillary forces, and formed a supported liquid membrane (SLM). The lumen of the hollow fiber was filled with a microliter amount of an acceptor phase (AP). The analytes were extracted from the donor phase (DP) into the organic solvent, and then captured into the AP. After extraction, the AP was directly injected into HPLC, 
GC, capillary electrophoresis (CE), or MS systems for final chemical analysis. Compared with polymeric membranes, the liquid membrane provides high mass-transfer rates and selectivity. Besides, it is compatible with a wide range of diverse organic liquids and additives, without compromising the stability of the membrane [13]. In addition, the high surface-to-volume ratio of the liquid membrane phases usually results in high enrichment efficiency of the analytes [14]. HF-LPME is also more robust than solvent LPME as the solvents are stabilized by the hollow fiber.

HF-LPME can be conducted at two- or three-phase mode [14,15]. That is, the AP used can either be the same organic solution as immobilized in the pores of the hollow fiber (two-phase extraction system), or an aqueous solution (three-phase extraction system). In two-phase HF-LPME, it is essential that the solubility of analytes in the organic solution is higher than in aqueous solution [15]. The analytes are transferred by diffusion from the samples into the organic AP. Three-phase HF-LPME includes extraction of the analytes from an aqueous sample into the organic membrane and a subsequent back extraction from the organic membrane into the aqueous acceptor solution. However, this extraction mode is limited to basic or acid analytes with ionisable functional groups [15]. In proton-driven three-phase system, the $\mathrm{pH}$ of AP is critical and should be ideally set to make the analytes completely ionized and thereby captured inside the AP. According to the general theory of supported liquid membrane with stagnant AP described by Jönsson et al. [16], the optimum condition for complete ionization of analytes is when the $\mathrm{pH}$ of AP is at least $3.3 \mathrm{pH}$ units lower than the $\mathrm{p} K_{\mathrm{a}}$ for basic analytes [8]. At the same time, the $\mathrm{pH}$ of DP should be adjusted to deprotonate the analytes and to suppress the solubility of analytes [14]. In recent years, HF-LPME by both two-phase [17-20] and three-phase mode [21-25] has been applied for various sample preparation procedures because of the major advantages such as high enrichment, clean-up and low solvent consumption. For the extraction of aromatic amines, Yazdi and Es'haghi reported the application of two-step hollow-fiber-based LLLPME [9]. The total enrichment factors of $>6000$ and detection limits of $\leq 250 \mathrm{ng} / \mathrm{L}$ were obtained. In the study of Zhao et al., threephase LLLME with hollow fiber was applied for the detection of four aromatic amines and the enrichment factors of 500 were obtained [26].

The four target aromatic amines in this work are aniline (ANL), 4-nitroaniline (NAL), 2,4-dinitroaniline (DNA) and dicloran (DCN), and they have significantly different values of $\log K_{\mathrm{OW}}$ and $\mathrm{p} K_{\mathrm{a}}$ as shown in Fig. 1. In view of their specific properties, three-phase HF-LPME was applied for aniline and 4-nitroanilne, whereas twophase HF-LPME was performed for 2,4-dinitroaniline and dicloran in the conventional extractions.

The goal of this study was to combine two- and three-phase HFLPME together, with TOPO as the anion carrier, to simultaneously extract all of the four analytes from environmental water samples. Parameters affecting the extraction were optimized and this proposed procedure was also applied to determine the concentration of target compounds in industrial wastewater.

\section{Experimental}

\subsection{Reagents and materials}

Aniline (99.5\%), 4-nitroaniline (99.0\%), 2,4-dinitroaniline (99.0\%) and dicloran (2,6-dichloro-4-nitroaniline, 98.5\%) were purchased from Dr. Ehrenstorfer GmbH (Augsburg, Germany). Tri$n$-octylphosphine oxide (TOPO), undecane and terrestrial origin humic acid sodium salt with $35.1 \%$ of dissolved organic carbon (DOC) were purchased from Sigma-Aldrich (Steinheim, Germany) and used as obtained. Dihexyl ether (DHE) was purchased from<smiles>Nc1ccccc1</smiles>

$$
\begin{aligned}
& \text { Aniline (ANL) } \\
& \text { pKa }=4.6 \\
& \text { Log Kow }=0.9
\end{aligned}
$$<smiles>Nc1ccc([N+](=O)[O-])cc1[N+](=O)[O-]</smiles>

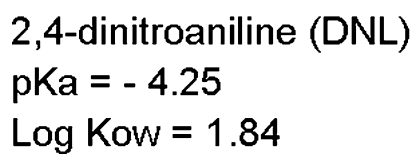<smiles>Nc1ccc([N+](=O)[O-])cc1</smiles>
4-nitroaniline (NAL) $\mathrm{pKa}=1$ Log Kow $=1.39$<smiles>Nc1c(Cl)cc([N+](=O)[O-])cc1Cl</smiles><smiles>N#[13C][18O][18O]</smiles>
$\mathrm{pKa}=-2.55$ Log Kow $=2.8$
Fig. 1. Structures of aniline, 4-nitroaniline, 2,4-dinitroaniline and dicloran and their $\mathrm{p} K_{\mathrm{a}}$ and $\log K_{\mathrm{OW}}$ values [28].

Tokyo Kasei Kogyo (Kita-Ku, Tokyo, Japan). HPLC-grade methanol was purchased from Mallinckrodt Baker (Phillipsburg, NJ, USA). All other chemicals were of analytical grade or above and ultrapure water purified by an Easypure LF system (Barnstead International, Dubuque, IA, USA) was used throughout.

The standard stock solution of aniline was prepared by dissolving $1 \mathrm{~mL}$ standard in $50 \mathrm{~mL}$ of HPLC-grade methanol. Individual standard stock solutions of the other three compounds $(1000 \mathrm{mg} / \mathrm{L})$ were prepared by dissolving $50 \mathrm{mg}$ of standards in $50 \mathrm{~mL}$ of HPLCgrade methanol. Working solutions were prepared by appropriate dilution of the stock solutions with water. The standard stock solutions and working solution were stored at $4{ }^{\circ} \mathrm{C}$.

Q3/2 Accurel PP polypropylene microporous hollow-fiber membrane (200 $\mu \mathrm{m}$ wall thickness, $600 \mu \mathrm{m}$ inner diameter, $0.2 \mu \mathrm{m}$ pore size, 75\% porosity), and 50/280 Accurel PP polypropylene hollowfiber tubing ( $50 \mu \mathrm{m}$ wall thickness, $280 \mu \mathrm{m}$ inner diameter, $0.1 \mu \mathrm{m}$ pore size, $60 \%$ porosity) were obtained from Membrana (Wuppertal, Germany). BD Micro-Fine Syringe (with a needle of $0.3 \mathrm{~mm}$ outer diameter and $8 \mathrm{~mm}$ length, $0.5 \mathrm{~mL}$, prepared for $\mathrm{U}-100$ insulin injection), obtained from BD Consumer Healthcare (Franklin Lakes, $\mathrm{NJ}$, USA) was used to fill the acceptor into the lumen of the hollow fiber for extraction and to flush out the acceptor.

\subsection{Extraction procedure}

The extraction procedure was carried out as described by Liu et al. [27]. The optimization procedure was conducted using $50 \mu \mathrm{g} / \mathrm{L}$ standard solutions. The extraction and preconcentration procedure for target analytes in water samples was as follows: (1) the hollow fiber was cut into segments with a length of $25 \mathrm{~cm}$. The fiber segment was cleaned with acetone by ultrasonication to remove any possible impurities and directly dried in air; (2) the acceptor solution was injected into the lumen of the fiber by using a BD Micro-Fine Syringe. Then, the fiber was submerged in the organic liquid for a few seconds to fill the membrane pores of the hollow 
fiber wall. After that, the lumen of the fiber was slowly flushed and completely filled with the acceptor (care was taken to avoid any air bubbles). Then, the two ends of the fiber were enveloped with aluminum foil and folded by metal wire binding. The looped fiber surface was washed with water to remove superfluous membrane liquid. The prepared extraction device was introduced into a $100 \mathrm{~mL}$ glass bottle with screw cap. It is worth noting that the fiber must be fully immersed in the sample solution. The extraction and enrichment was performed by shaking using DDHZ-300 multipurpose desk homothermal shaker (Taicang Experimental Instrument Factory, Jiangshu, China) at $200 \mathrm{rpm}$ at $25^{\circ} \mathrm{C}$. At the end of the extraction, the hollow fiber extraction device was taken out from the bottle and one of the sealed ends was carefully cut and connected to the needle of a BD Micro-Fine Syringe filled with $50 \mu \mathrm{L}$ methanol. Then the other sealed end was cut and methanol was slowly flushed through the lumen to simultaneously transfer analytes both in the acceptor phase $(10 \mu \mathrm{L})$ and the membrane phase into a clean and dry glass insert tube $(200 \mu \mathrm{L}$, Alltech, Deerfield, IL, USA). The whole elution solution was adjusted with $3 \mu \mathrm{L}$ of $5 \mathrm{M}$ $\mathrm{NaOH}$. Then $20 \mu \mathrm{L}$ of the adjusted elution solution was injected for HPLC analysis.

\subsection{HPLC analysis and real samples}

Chromatographic analyses were performed by Agilent (Wilmington, DE, USA) 1100 series HPLC system equipped with Agilent G1312A Binpump and an Agilent G1314 VW detector. An Eclipse $\mathrm{XDB}-\mathrm{C}_{18}$ column $(150 \mathrm{~mm} \times 4.6 \mathrm{~mm}$, particle size $5 \mu \mathrm{m})$ was used as the analytical column.

HPLC separation of aromatic amines was conducted by using a mixture of methanol and $0.02 \mathrm{~mol} / \mathrm{L} \mathrm{Na}_{2} \mathrm{HPO}_{4}$-citric acid buffer (adjusted $\mathrm{pH} 7.2$ with $\mathrm{NH}_{4} \mathrm{OH}$ ) at a flow rate of $1 \mathrm{~mL} / \mathrm{min}$ and the detection was carried out at a wavelength of $254 \mathrm{~nm}$. In this present experiment, baseline separation and better chromatographic peak shapes were obtained by using a mixture buffer of $\mathrm{Na}_{2} \mathrm{HPO}_{4}$-citric acid. The gradient profile was as follows: start at $20 \%$ methanol, linear increase to $39.5 \%$ methanol in $0-10 \mathrm{~min}$ and then linear increase to $75 \%$ methanol in $10-14 \mathrm{~min}$ and last $4 \mathrm{~min}$, thereafter restore to $20 \%$ in 1 min followed by a 2 min post-run step.

Municipal sewage water samples were collected from the export of Gaobeidian sewage treatment plant (Beijing, China) in June 2008. Tap water sample was freshly collected from our laboratory. Other water samples were the surface water collected from a local river and lake in Beijing suburbs. All samples were stored in $1 \mathrm{~L}$ brown glass bottles at $4{ }^{\circ} \mathrm{C}$. Spiked samples were prepared as working solutions, with the addition of $1 \mathrm{M} \mathrm{Na}_{2} \mathrm{SO}_{4}$. The $\mathrm{pH}$ was adjusted with $5 \mathrm{M} \mathrm{NaOH}$.

\subsection{Calculations}

All results were expressed as mean values of at least three replicates in the experiments. The enrichment factor (EF) of the analyte was calculated by the following equation:

$E F=\frac{C_{A P, \text { final }}}{C_{D P, \text { initial }}}$

In this equation, $C_{D P \text {, initial }}$ and $C_{A P \text {, final }}$ are the initial analytes concentration in the donor phase and final analytes concentration in the acceptor phase, respectively. $C_{A P}$, final of each analyte was calculated from the calibration curves by directly injecting $20 \mu \mathrm{L}$ of different concentrations of standards into the HPLC system. The concentrations of analytes in environmental samples were determined by the prescribed procedure and calculated from the standard curve.

\section{Results and discussion}

The $\mathrm{p} K_{\mathrm{a}}$ and $\log K_{\mathrm{OW}}$ values of the four selected model compounds shown in Fig. 1 indicate they are especially challenging analytes to be simultaneously extracted by either a single twophase LPME or a single three-phase LPME. Because ANL and NAL are ionizable basic compounds, both of them are transported between the acceptor and the donor phase by the gradient of $\mathrm{pH}$; whereas DNL and DCN have very small $\mathrm{p} K_{\mathrm{a}}$ values, so they are difficult to be ionized and back extracted into the acidic acceptor phase. Therefore, a three-phase LPME is suitable for the first two analytes whereas a two-phase extraction mode is more suitable for the latter two compounds. By comprehensive consideration of the amino group in the structures of the four compounds, the same transporting mechanism from the DP into the organic membrane phase was achieved by the addition of a carrier in the membrane solvent. Relevant experimental parameters were optimized for the extraction of the four analytes.

\subsection{Selection of hollow fiber}

Two kinds of polypropylene hollow fiber membrane, Q3/2 Accurel and 50/280 Accurel, were tested as liquid membrane support. Their profiles of EF against extraction time were obtained by conducting the proposed extraction procedure. The extraction was carried out as follows: $50 \mu \mathrm{g} / \mathrm{L}$ each compound spiked in $50 \mathrm{~mL}$ of $0.1 \mathrm{M} \mathrm{NaOH}$ as DP; $10 \mu \mathrm{L}$ of $2 \mathrm{M} \mathrm{HCl}$ as AP; DHE as liquid membrane. The EF of the target analytes was lower by 2-3 times when Q3/2 Accurel membranes was used compared to that by 50/280 Accurel membranes, probably because the specific surface area of 50/280 Accurel was higher than that of Q3/2 Accurel and thus resulted in the higher adsorptive capacity. Therefore, 50/280 Accurel was selected in the following experiments.

\subsection{Selection of organic membrane solvent}

For both the two- and three-phase LPME system, it is crucial to select a proper organic solvent as the liquid membrane for the hollow fiber. DHE and undecane, the typical polar and nonpolar solvent for liquid membrane used in LPME, were tested. The results showed that when using DHE as membrane solvent, the EF (15-35) was higher at least one-third than that by undecane. In theory, the results were consistent with the principle of like dissolves like. Thus, DHE was utilized for subsequent experiments.

\subsection{Selection of TOPO content in liquid membrane}

In the preliminary experiments, transportation of target compounds was driven by passive diffusion from the $\mathrm{DP}$ (adjusted to $\mathrm{pH}$ 13 with $5 \mathrm{M} \mathrm{NaOH}$ ) through different organic solvents immobilized in the pores of a hollow fiber, into the AP $(2 \mathrm{M} \mathrm{HCl})$. Under these conditions, relatively lower EFs were obtained both for undecane (3.3) and for DHE (no more than 35). Thus, it was desirable to add a carrier compound in the liquid membrane to obtain higher and more practicable EFs. Typically, TOPO was efficiently used for polar organic analytes with low $\mathrm{p} K_{\mathrm{a}}$ and $K_{\mathrm{OW}}$ [29-31] due to the hydrogen bonding between TOPO and the analytes. Not as expected, the initial addition of TOPO into DHE did not remarkedly improve the extraction efficiency of DNL and DCN. It indicated that DNL and DCN were not trapped into the AP and might remain in the liquid membrane phase. Therefore, pilot experiments were performed by slowly injecting a flow of methanol through the fiber lumen to harvest the analytes in both the acceptor and the membrane phase. The results showed that the extraction of all analytes was improved. In detail, there were two kinds of elution modes: (1) one-step elution 

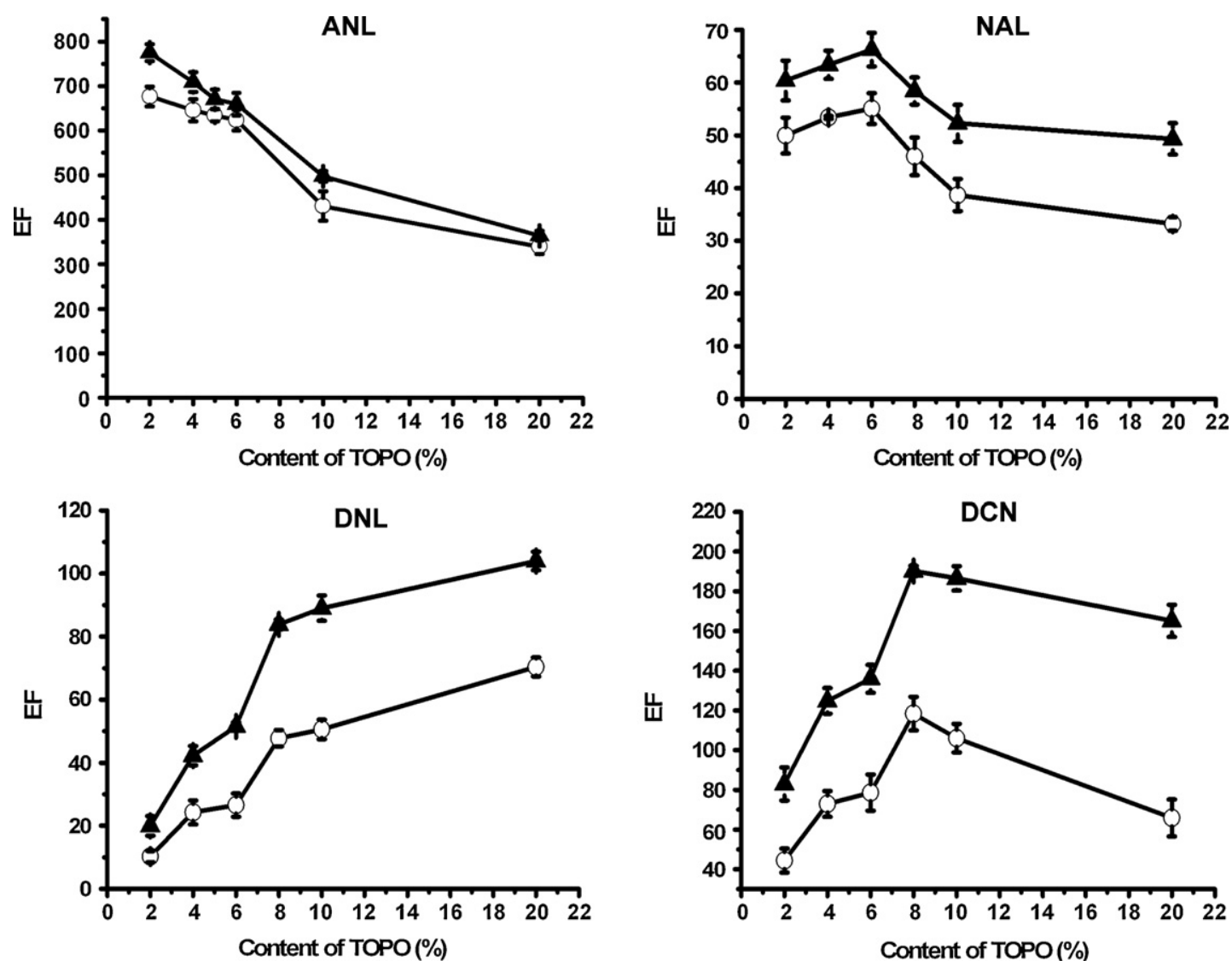

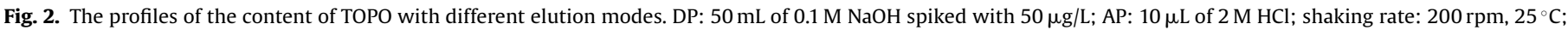
shake time: $30 \mathrm{~min}$; liquid membrane: DHE with TOPO. (匹) One-step elution mode; $(X)$ two-step elution mode.

mode: the flow of methanol was directly injected through the hollow fiber to elute the AP and the membrane liquid altogether at once; (2) two-step elution mode: the AP was firstly flushed from the hollow fiber then the flow of methanol was injected through the hollow fiber to capture the extracts in the liquid membrane. These two different elution modes were investigated with different contents of TOPO in the liquid membrane, and the results were shown in Fig. 2. Consistent trends of EF against the content of TOPO were obtained by the two-elution modes. Generally speaking, the one-step elution mode obtained higher EFs. On the other hand, the four analytes showed very different extraction behaviors with the increase of the TOPO content (Fig. 2). It was seen that with the increase of TOPO content, the extraction EF of ANL decreased gradually, whereas that of NAL had no obvious change and DCN achieved the maximum at $8 \%$ TOPO in the membrane, and the extraction efficiency of DNL increased throughout the selected TOPO contents. In this case, the addition of TOPO in the membrane could result in the increase of extraction flux and the difficulty of back extraction into AP at the same time. As a compromise for the behaviors of the four analytes, $8 \%$ TOPO in membrane liquid and the one-step elution mode were adopted for the subsequent experiments.

Further, in order to investigate the extraction efficiency of the one-step elution mode, the volume of methanol and the time of elution were examined in manner of four combinations: the one-time elution by $20 \mu \mathrm{L}$ methanol, two-time elution by $20 \mu \mathrm{L}$ methanol, one-time elution by $50 \mu \mathrm{L}$ methanol and two-time elution by $50 \mu \mathrm{L}$ methanol. Following the four elution manners, the fibers were eluted additionally by more methanol until analytes were not determined in the elution solutions. Then, the elution solutions except for those of the four manners were collected to determine residual analytes in the fibers. The relative extraction efficiency of the four elution manners was evaluated by the percentage of the extractions amount. As shown in Fig. 3, for ANL and NAL, the extraction efficiencies did not significantly vary with volume and times of elution and achieved more than 90\%; whereas for DNL and DCN, the extraction efficiencies had no obvious changes with different elution times, but these were remarkably increased with different methanol volumes, i.e., with $50 \mu \mathrm{L}$ methanol, the extraction

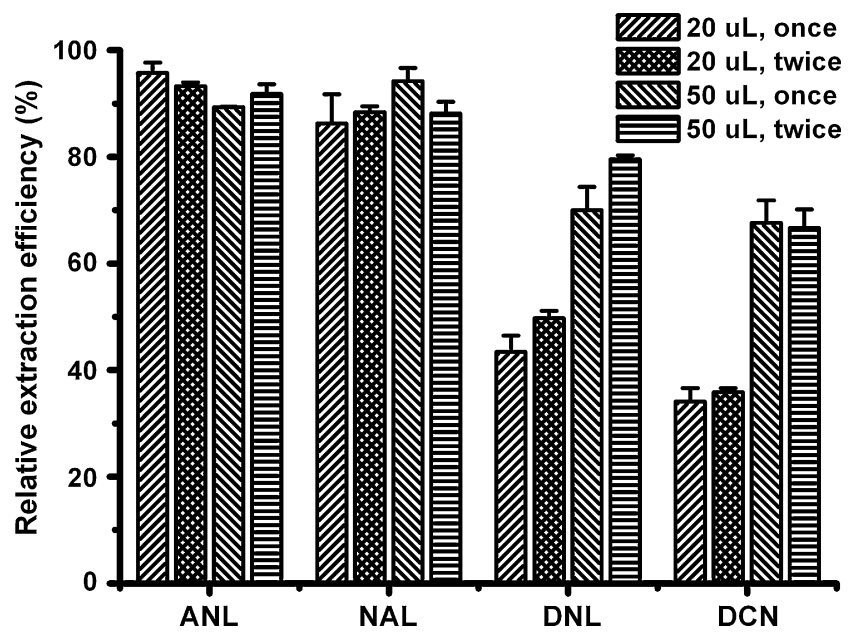

Fig. 3. The profiles of the extraction efficiency against different methanol volumes and elution times. DP: $50 \mathrm{~mL}$ of $0.1 \mathrm{M} \mathrm{NaOH}$ spiked with $50 \mu \mathrm{g} / \mathrm{L}$; AP: $10 \mu \mathrm{L}$ of $2 \mathrm{M}$ $\mathrm{HCl}$; shaking rate: $200 \mathrm{rpm}, 25^{\circ} \mathrm{C}$; shake time: $30 \mathrm{~min}$; liquid membrane: DHE with $8 \%$ TOPO. 
efficiencies increased from approximately $30 \%$ to $80 \%$ and $70 \%$, respectively. As the non-exhaustive extraction procedure was used in the present experiment, above $70 \%$ of the extraction efficiencies could satisfy the determination in the following experiments, even if the extraction efficiencies of DNL and DCN continued increasing with even larger volume of methanol. Thus, the elution was conducted by the way of $50 \mu \mathrm{L}$ methanol and one-time.

\subsection{Selection of $\mathrm{pH}$}

The extraction efficiency and selectivity of the SLM extraction is controlled by several parameters such as the $\mathrm{pH}$ of DP and AP as well as the composition of organic solvents in the pores of hollow fiber. As mentioned above, the basic principle of SLM is that the $\mathrm{pH}$ of donor phase should ensure that the analytes are in their uncharged states and the $\mathrm{pH}$ of acceptor phase should be at least $3.3 \mathrm{pH}$ units below the $\mathrm{pH}$ of target basic analytes. For the basic compounds with $\mathrm{p} K_{\mathrm{a}} \leq 2$, the $\mathrm{pH}$ of acceptor phase was found to be the limiting factor in attaining high extraction efficiency because the condition for complete trapping was not fully met. Therefore, the $\mathrm{pH}$ values of donor and acceptor phase were optimized to obtain the highest EFs.

For the basic model analytes, $\mathrm{pH}$ was adjusted into the alkaline region to ensure deprotonation. In a series of experiments, the concentration of $\mathrm{NaOH}$ in the sample was varied from $0.01 \mathrm{M}$ to $0.3 \mathrm{M}$. The results demonstrated that there was no significant effect from $0.01 \mathrm{M}$ to $0.1 \mathrm{M} \mathrm{NaOH}$, and this was in agreement with expectations that $0.01 \mathrm{M} \mathrm{NaOH}$ was enough to deionize all of analytes. From the view of practical application, $\mathrm{pH} 13$ of DP was selected. In the extraction of real environmental water samples, the $\mathrm{pH}$ value was firstly adjusted to $\mathrm{pH} 13$ with $5 \mathrm{M} \mathrm{NaOH}$.

A similar experiment was also conducted for the selection of $\mathrm{pH}$ of the AP. In this case, the pH of AP is only the direct controlling factor of the EFs of ANL and NAL, of which complete ionization could be fully accomplished. The result from the optimized AP pH showed that by using $0.1 \mathrm{M} \mathrm{NaOH}$ as DP, the extraction efficiency of ANL and NAL increased with the increased concentration of $\mathrm{HCl}$ and the obtained maximum EFs were 700 for ANL and 380 for NAL at $8 \mathrm{M}$ $\mathrm{HCl}$. The concentration of deionized analytes in the AP increased with the extraction time. Conversely, more and more higher concentration of analytes back extracted into the AP inhibited the further transport across the supported hollow fiber membrane. The equilibrium between the DP, AP and membrane phase was reached. Therefore, $8 \mathrm{M} \mathrm{HCl}$ was adopted as the AP in the following studies.

\subsection{Effect of volume ratio of donor to acceptor phase}

The influence of DP volume was further studied, with a constant AP volume of $10 \mu \mathrm{L}$ and extraction time of $30 \mathrm{~min}$. The results are shown in Fig. 4. The EF of ANL increased rapidly from the volume of $50 \mathrm{~mL}$ to $100 \mathrm{~mL}$ and reached maximum at $500 \mathrm{~mL}$. The EFs of three other target analytes had no notable changes with the increase of DP volume. The reason for these phenomena was not clear. Probably, it is because of the differences of the substitute groups and the molecular structure that the fixed stoichiometry and the competitive bonding mechanism of the formation of hydroxyl bond with TOPO were different. On the other hand, the EFs of target analytes were dependent on both the recovery and the donor-acceptor phase ratio. Theoretically, relative lower sample volume may be preferred to provide higher extraction recoveries and reduce the extraction time. Besides, TOPO leakage happened with larger donor volume in present experiments. The results showed higher analyte enrichment had been obtained at about $100 \mathrm{~mL}$ of DP into a microliter AP. Therefore, subsequent experiments were conducted with $100 \mathrm{~mL} \mathrm{DP}$ and $10 \mu \mathrm{L} \mathrm{AP}$.

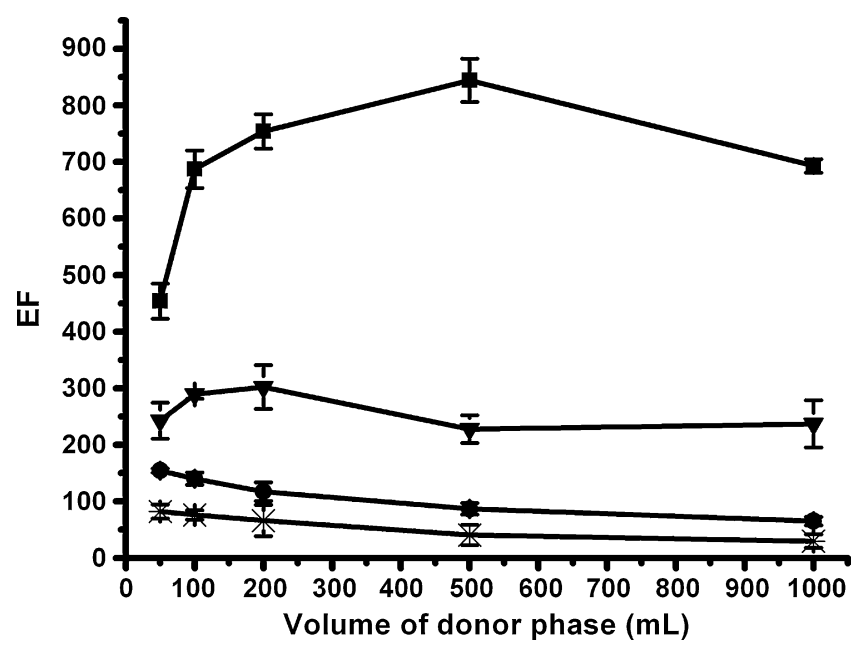

Fig. 4. The effect of the DP volume on the EF of analytes. DP: $0.1 \mathrm{M} \mathrm{NaOH}$ spiked with $50 \mu \mathrm{g} / \mathrm{L} ; \mathrm{AP}: 10 \mu \mathrm{L}$ of $8 \mathrm{M} \mathrm{HCl}$; shaking rate: $200 \mathrm{rpm}, 25^{\circ} \mathrm{C}$; shake time: $30 \mathrm{~min}$; liquid membrane: DHE with $8 \%$ TOPO. ( $)$ ANL; $(\mathcal{*})$ NAL; $(\bullet)$ DNL; $(\boldsymbol{v})$ DCN.

\subsection{Effect of ion strength in donor phase}

The salting-out effect can increase the partition coefficient of polar analytes to the organic liquid. By increasing the ionic strength of the donor solution, the enrichment factor of these weakly basic anilines could correspondingly be increased. Besides, it was reported that the increased ionic strength of the donor solution could also enhance the stability of the membrane liquid, as a result of inhibiting emulsion formation, which could affect the membrane instability [15]. The effect of DP ionic strength on the enrichment factor was therefore, investigated by the addition of $\mathrm{Na}_{2} \mathrm{SO}_{4}$. As seen from Fig. 5, the amount of extracts increased with the increased concentration of $\mathrm{Na}_{2} \mathrm{SO}_{4}$ in the donor phase. However, the increasing trend of extracts amount was not significant when the concentration of $\mathrm{Na}_{2} \mathrm{SO}_{4}$ was more than $1 \mathrm{M}$. The phenomenon could be probably led by the common action of salting-out effect and electrostatic effect. At the beginning of the extraction, the salting-out effect played a leading role, which impelled the analytes from the DP into the fiber membrane. With the further increased concentration of $\mathrm{Na}_{2} \mathrm{SO}_{4}$, the electrostatic effect was produced between the analytes and $\mathrm{Na}^{+}$and $\mathrm{SO}_{4}{ }^{2-}$, which resulted in the

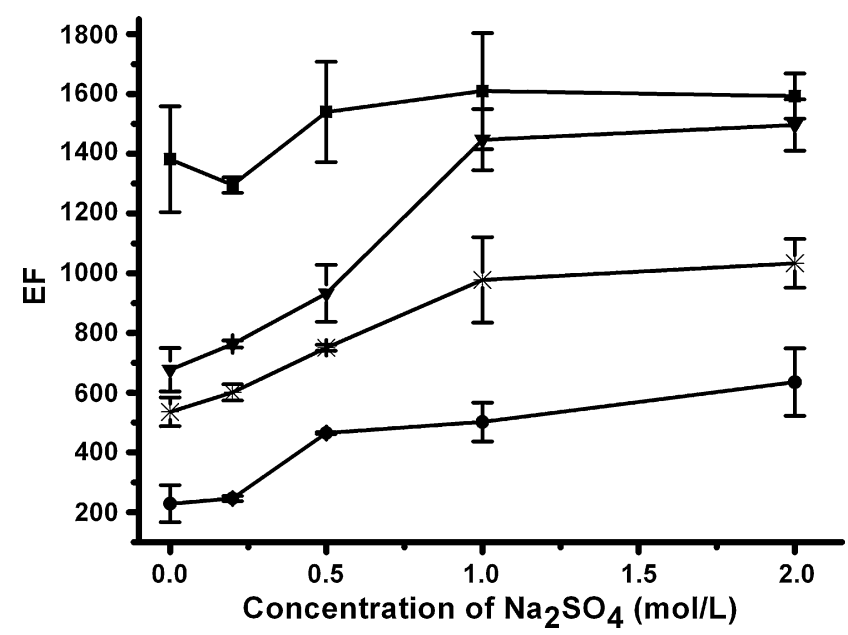

Fig. 5. The effect of the concentration of $\mathrm{Na}_{2} \mathrm{SO}_{4}$ in donor phase on the extraction amount of analytes. DP: $100 \mathrm{~mL}$ of $0.1 \mathrm{M} \mathrm{NaOH}$ spiked with $50 \mu \mathrm{g} / \mathrm{L} ; \mathrm{AP}: 10 \mu \mathrm{L}$ of $8 \mathrm{M}$ $\mathrm{HCl}$; extraction time: $30 \mathrm{~min}$; shaking rate: $200 \mathrm{rpm}, 25^{\circ} \mathrm{C}$; liquid membrane: DHE

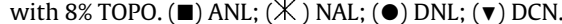




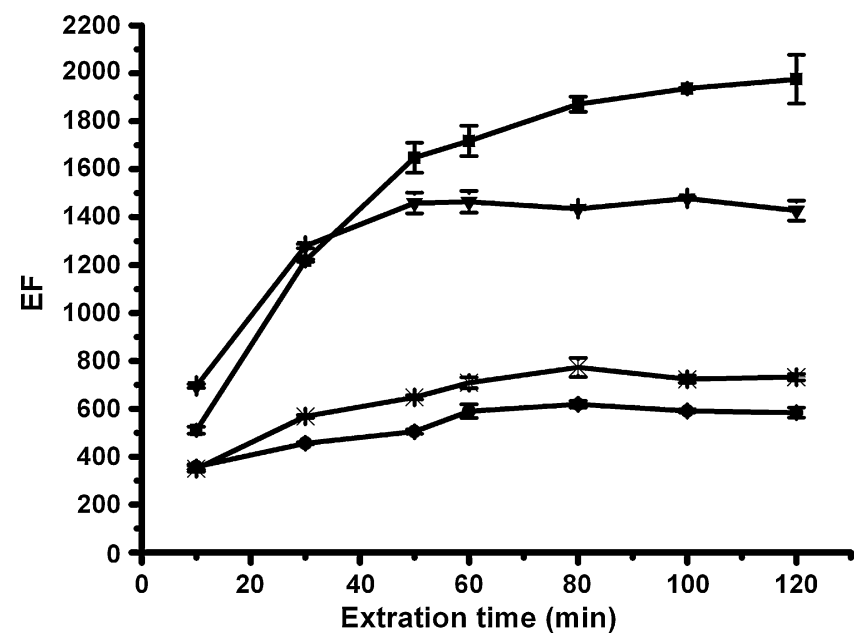

Fig. 6. The effect of the extraction time on EFs of analytes. DP: $100 \mathrm{~mL}$ of $0.1 \mathrm{M}$ $\mathrm{NaOH}$ spiked with $50 \mu \mathrm{g} / \mathrm{L}$; AP: $10 \mu \mathrm{L}$ of $8 \mathrm{M} \mathrm{HCl}$; shaking rate: $200 \mathrm{rpm}, 25^{\circ} \mathrm{C}$; liquid

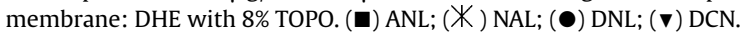

difficult extraction of analytes and the decrease of the extraction efficiency. In the following experiments and the analysis of environment water samples, $1 \mathrm{M} \mathrm{Na}_{2} \mathrm{SO}_{4}$ was added into the DP to improve the extraction efficiency.

\subsection{Effect of extraction time}

LPME based on two- or three-phases are considered as equilibrium extraction techniques. During the extraction procedure, increasing the extraction time could make the extraction completely. Fig. 6 illustrates the profiles of the extraction factors against the extraction time. The results showed that the EFs were reached maxima at $80 \mathrm{~min}$ for all the four analytes. After $80 \mathrm{~min}$, the extraction of all analytes reached the equilibrium. Thus, the extraction time of 80 min was selected to obtain higher enrichment factor.

\subsection{Matrix effect}

In order to investigate the influence of the matrix on the extraction process, standard solutions with humic acid (0-25 mg/L DOC) were extracted under the optimized conditions. The relative extraction efficiency, defined as the ratio of HPLC peak areas in humic acid present solutions to humic acid absent solutions extracts of

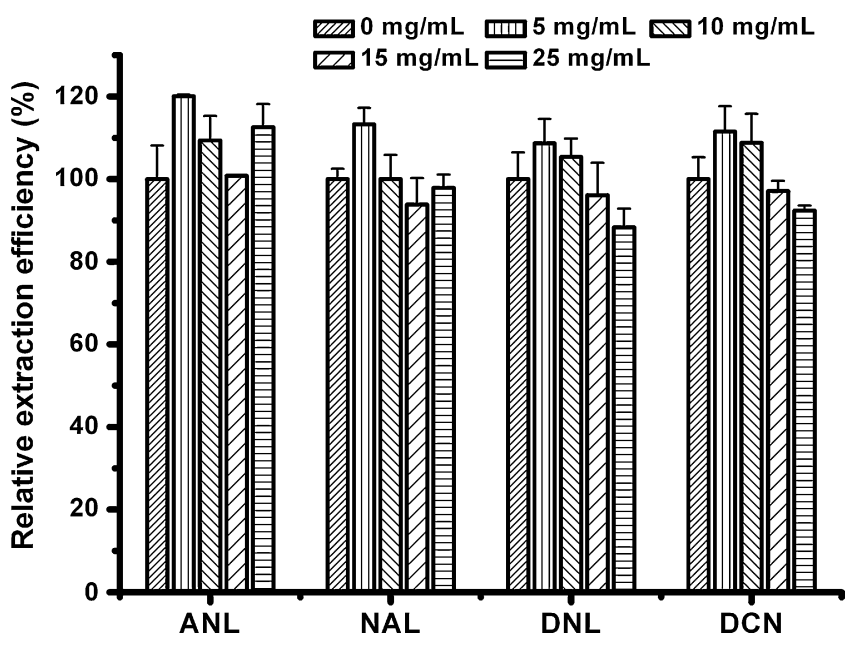

Fig. 7. The matrix effect on the extraction efficiency. DP: $100 \mathrm{~mL}$ of $0.1 \mathrm{M} \mathrm{NaOH}$ spiked with $50 \mu \mathrm{g} / \mathrm{L}$; AP: $10 \mu \mathrm{L}$ of $8 \mathrm{M} \mathrm{HCl}$; extraction time: $80 \mathrm{~min}$; shaking rate: $200 \mathrm{rpm}, 25^{\circ} \mathrm{C}$. Liquid membrane: DHE with $8 \%$ TOPO.

standard solution was employed for evaluation. Fig. 7 shows that the relative extraction efficiencies were in the range of $88-120 \%$ for all the studied compounds at different humic acid concentrations, indicating the extraction procedure eliminated interference of matrix in the environment.

\subsection{Evaluation of the method performance}

Under the optimized conditions, calibration curves were plotted using seven spiking levels of analytes in the concentration range of 5-200 $\mu \mathrm{g} / \mathrm{L}$. For each level, three replicate extractions were operated. The LODs were calculated at a signal-to-noise ratio of 3 . The performance of the LPME system in terms of corresponding regression equation, correlation coefficient $(R)$, linear ranges (LR) and the limits of detection (LODs) were calculated and summarized in Table 1 . These results demonstrated the proposed method was very good.

\subsection{Application in environmental water samples analysis}

In order to assess the applicability of the newly developed method to real samples, the proposed procedure was applied to determine the four analytes in environmental water samples. As

Table 1

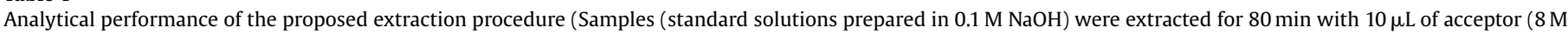
$\mathrm{HCl}$ ) by using DHE with 8.0\% TOPO as membrane liquid.).

\begin{tabular}{|c|c|c|c|c|c|}
\hline Compounds & Linear range $(\mu \mathrm{g} / \mathrm{L})$ & Correlation equation & Correlation coefficient & Enrichment factor & Detection limit $(\mu \mathrm{g} / \mathrm{L})$ \\
\hline ANL & $5-200$ & $y=3.230 x-15.04$ & 0.9985 & 2000 & 1.5 \\
\hline NAL & $5-200$ & $y=2.500 x+15.20$ & 0.9982 & 745 & 1.5 \\
\hline DNL & $5-200$ & $y=3.322 x+8.906$ & 0.9997 & 407 & 0.8 \\
\hline DCN & $5-200$ & $y=3.937 x+1.097$ & 0.9976 & 1020 & 0.5 \\
\hline
\end{tabular}

Table 2

Analyte concentration $(C, \mu \mathrm{g} / \mathrm{L})$ and spike recovery $(R, \%)$ in samples by the proposed method.

\begin{tabular}{|c|c|c|c|c|c|c|c|c|}
\hline \multirow[t]{2}{*}{ Sample } & \multicolumn{2}{|c|}{ ANL } & \multicolumn{2}{|c|}{ NAL } & \multicolumn{2}{|l|}{ DNL } & \multicolumn{2}{|l|}{ DCN } \\
\hline & C & $R$ & C & $R$ & C & $R$ & C & $R$ \\
\hline Municipal sewage sample & 7 & 81 & 18 & 94 & 19 & 91 & 11 & 85 \\
\hline Lake water & ND & 96 & 0.8 & 92 & 1.5 & 103 & 3.6 & 89 \\
\hline River water & ND & 94 & 9.2 & 100 & 11.1 & 82 & 12.9 & 101 \\
\hline Tap water & ND & 83 & ND & 82 & 2.8 & 93 & 11 & 81 \\
\hline Well water & ND & 85 & ND & 80 & 3 & 88 & 2.9 & 90 \\
\hline
\end{tabular}

ND: not detected. $C$ was determined without spiking. $R$ was determined by spiking $5 \mu \mathrm{g} / \mathrm{L}$ of analytes. 

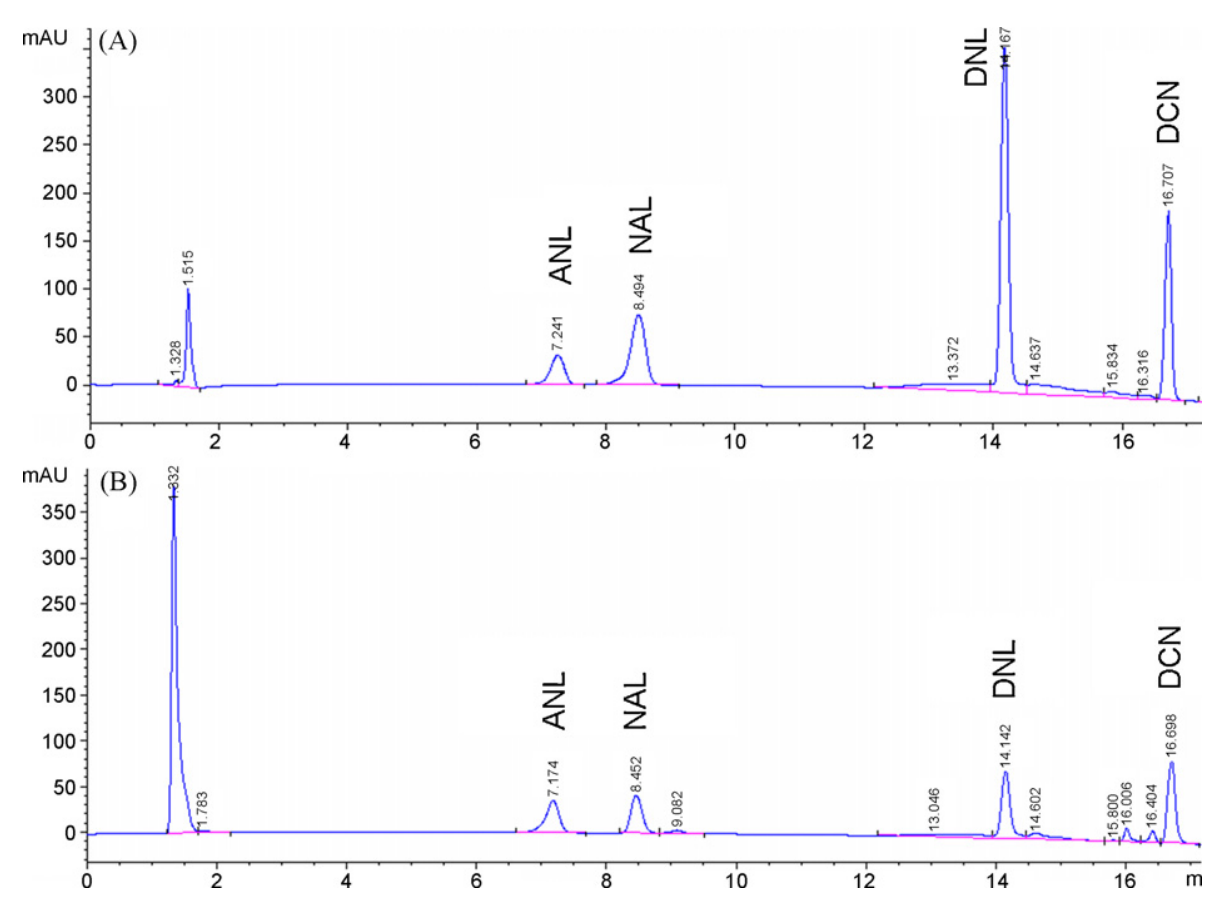

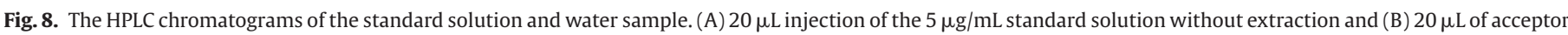
phase after extraction from water sample spiked with $5 \mu \mathrm{g} / \mathrm{L}$ of each analyte under the optimal extraction condition.

shown in Table 2, all the four target compounds were detected in municipal sewage sample and DNL and DCN were detected in all the samples. To evaluate the spiked recovery, the water samples were extracted after spiking with $5 \mu \mathrm{g} / \mathrm{L}$ each of the analytes. As shown in Table 2, good spike recoveries (80-103\%) were obtained. Fig. 8A shows the HPLC chromatogram of $5 \mu \mathrm{g} / \mathrm{mL}$ standard solution without extraction and Fig. 8B showed the HPLC chromatogram of $20 \mu \mathrm{L}$ acceptor phase after extraction from the spiking water sample with $5 \mu \mathrm{g} / \mathrm{L}$ of each analyte. It was obvious that the chromatograms illustrated no interferences in analysis.

\section{Conclusions}

In the present work, a two-/three-phase LPME performed in a single step was developed for the extraction of trace level amounts of aromatic amines with very different $\log K_{\mathrm{OW}}$ and $\mathrm{p} K_{\mathrm{a}}$ values. With the help of an appropriate carrier, in this case TOPO, the equilibrium extraction could be established to provide higher enrichment factors and acceptable recoveries. The extraction was carried out directly without any other pretreatment and the eluted analytes were directly determined with HPLC. Results showed that the procedure combined with HPLC was economically and practically feasible for the analysis of target compounds in various environmental water samples with complex matrices.

\section{Acknowledgements}

The present study was supported by the High-Tech Research and Development Program of China (2007AA06A407, 2007AA06Z413) and the National Natural Science Foundation of China (20621703).

\section{References}

[1] H. Kataoka, J. Chromatogr. A 733 (1996) 19.
[2] R.D. Voyksner, R. Straub, J.T. Keever, H.S. Freeman, W.W. Hsu, Environ. Sci. Technol. 27 (1993) 1665.

[3] R.J. Lewis, Sax's Dangerous Properties of Industrial Materials, 8th ed., Van Nostrand Reinhold, New York, 1992.

[4] K.T. Chung, Ecotoxicol. Rev. C18 (2000) 51.

[5] EPA Method 1625, Fed. Reg. US Government Print Office, Washington, DC September 1994

[6] EPA Method 8270B, Fed. Reg. US Government Print Office, Washington, DC, September 1994.

[7] D. Puig, D. Barcelo, Trends Anal. Chem. 15 (1996) 362.

[8] J. Patsias, E. Papadopoulou-Mourkidou, J. Chromatogr. A 904 (2000) 171.

[9] A. Sarafra Yazdi, Z. Es'haghi, J. Chromatogr. A 1082 (2005) 136.

[10] M. Longo, A. Cavallaro, J. Chromatogr. A 753 (1996) 91.

[11] J.S. Chiang, S.D. Huang, Talanta 75 (2008) 70.

[12] S. Pedersen-Bjergaard, K.E. Rasmussen, Anal. Chem. 71 (1999) 2650.

[13] L. Chimuka, N. Megersa, J. Norberg, L. Mathiasson, J.Á. Jönsson, Anal. Chem. 70 (1998) 3906

[14] S. Pedersen-Bjergaard, K.E. Rasmussen, J. Chromatogr. A 1184 (2008) 132.

[15] K.E. Rasmussen, S. Pedersen-Bjergaard, Trends Anal. Chem. 23 (2004) 1.

[16] J.Å. Jönsson, P. Lövkvist, G. Audunsson, G. Nilvé, Anal. Chim. Acta 277 (1993) 9.

[17] S. King, J.S. Meyer, A.R.J. Andrews, J. Chromatogr. A 982 (2002) 201.

[18] S. Müller, M. Möder, S. Schrader, P. Popp, J. Chromatogr. A 985 (2003) 99.

[19] L. Hou, G. Shen, H.K. Lee, J. Chromatogr. A 985 (2003) 107.

[20] L. Zhao, H.K. Lee, Anal. Chem. 74 (2002) 2486.

[21] L. Zhu, K.H. Ee, L. Zhao, H.K. Lee, J. Chromatogr. A 963 (2002) 335.

[22] A. Sarafraz Yazdi, Z. Es'haghi, J. Chromatogr. A 1094 (2005) 1.

[23] M.B. Melwanki, W.H. Hsu, S.D. Huang, Anal. Chim. Acta 552 (2005) 67.

[24] T.S. Ho, J.L.E. Reubsaet, H.S. Anthonsen, S. Pedersen-Bjergaard, K.E. Rasmussen, J. Chromatogr. A 1072 (2005) 29.

[25] H.G. Ugland, M. Krogh, L. Reubsaet, J. Chromatogr. B 798 (2003) 127.

[26] L. Zhao, L.Y. Zhu, H.K. Lee, J. Chromatogr. A 963 (2002) 239.

[27] J.F. Liu, L. Toräng, P. Mayer, J.Å. Jönsson, J. Chromatogr. A 1160 (2007) 56.

[28] http://www.syrres.com/eSc/tscats.htm, the web database of Syracuse Research Corporation (SRC) is about the area of environment science.

[29] Y. Shen, V. Obuseng, L. Grönberg, J.Å. Jönsson, J. Chromatogr. A 725 (1996) 189.

[30] D.W. Kou, X.Y. Wang, S. Mitra, J. Chromatogr. A 1055 (2004) 63.

[31] G.H. Zhao, J.F. Liu, M. Nyman, J.Å. Jönsson, J. Chromatogr. B 846 (2007) 202. 